\title{
Construction of a multi-regional input-output table for Nagoya metropolitan area, Japan
}

\author{
Mitsuo Yamada
}

Correspondence: yamada@mecl. chukyo-u.ac.jp

School of Economics, Chukyo University, 101-2 Yagoto-Honmachi, Showa-ku, Nagoya City 466-8666, Japan

\section{Springer}

\begin{abstract}
Japan has many input-output tables, national and regional. We focus on the Nagoya metropolitan area, in which Toyota Motors is headquartered along with many industries manufacturing transport equipment, machine tools and other machinery. This area is included in the region covered by three prefectures; Aichi, Gifu, and Mie. To construct a multi-regional input-output table from these prefectures, we first break down each prefecture table with 186 sectors into several smaller sub-regional tables. Then we combine each table into one multi-regional input output table, consisting of 14 sub-regions. Transaction values among sub-regions of each sector are estimated by the gravity-RAS method, in which the initial values are obtained by the gravity model. Using the multi-regional table, we discuss the structural characteristics of the Nagoya metropolitan area. We then show a way to cope with the various inconsistencies of regional definitions, administrative and economic, in the input-output analysis.
\end{abstract}

Keywords: Multi-regional input-output table; Gravity-RAS method; Average Propagation Lengths; Nagoya metropolitan area; Crosshauling

JEL Classification: R15; R12

\section{Introduction}

In Japan, all of 47 prefectures have released their input-output tables (hereafter IOTs) for every 5 years beginning with 1990. The prefectures' IOTs have been effectively used for the evaluation of many events, the policy evaluation of local governments, and the economic planning of the regions. Recently, the prefectures' tables have been applied to compile them into a multi-regional IOT (hereafter MRIOT). This tendency stems from the recognition that the multi-regional input-output analysis becomes more important, because the regional economies are strongly connected domestically and internationally.

It is well known that there are two types in the MRIOT, Isard-type and CheneryMoses-type (Miller and Blair (2009)). They differ in the assumption of interregional trade coefficient. The former require a complete set of intra- and interregional data, though it is difficult to obtain such interregional trade coefficients for each sector in each region, especially within a country. On the other hand, the latter has advantages in compiling the table, because of the simplification in applying the common interregional trade coefficient for each sector in each region. For this reason, MRIOTs within a country usually have been compiled as Chenery-Moses type. Nevertheless, the interregional trade data within a country are still difficult to obtain fully, which forces one

(c) 2015 Yamada. This is an Open Access article distributed under the terms of the Creative Commons Attribution License (http:// creativecommons.org/licenses/by/4.0), which permits unrestricted use, distribution, and reproduction in any medium, provided the original work is properly credited. 
to shift from adopting the survey method to some kind of non-survey method in the estimation of the interregional trade coefficients. LQ techniques, gravity model, RAS method, and others have been developed or applied for such estimation. Lahr (1993) reviewed typical regional input-output models from 1963 to 1992 and pointed out the importance of the hybrid approach, both survey-based and non-survey, to construct an accurate input-output table with reasonable costs.

Cross-hauling (the simultaneous exporting and importing of one and the same type of product) is important in interregional trade, because ignoring it induces the underestimation of trade and overestimation of regional output multiplier (see Kronenberg (2009)). LQ techniques are easy to manipulate at least for two regions, though the techniques have the disadvantage that the cross-hauling is inevitably eliminated in the interregional trade. The gravity model, which originally stems from the theory in Physics, is applied to explain the commodity flows among regions, allowing cross-hauling in the interregional trade. The RAS method is originally developed for the estimation of the input output coefficients, for which only the peripheral information of the columnsums and the row-sums is known, in the iterative way. This method requires initial values, on which the solution depends. Sargento et al. (2012) compared and assessed the performance of some gravity models for explaining the interregional trade among regions. Nakano and Nishimura (2013) estimated one type of gravity model with crosshauling using a survey on interregional transactions and constructed three-regional IOTs of Japan.

In this paper, using the IOTs for the three prefectures of Aichi, Gifu, and Mie, respectively, we recompile them into one type of MRIOT for the Tokai Region covering those prefectures. For this purpose, we first break down each prefecture's table into the tables for several small areas. Then the commodity flows among the areas for each sector are estimated by the Gravity-RAS method, in which the initial values for RAS iterative calculation are reduced from the estimated Gravity model. Finally, we integrate all the small area tables into a MRIOT, using the estimated transaction shares of the commodity flows. This MRIOT for the Tokai Region consists of 186 sectors for each of the 14 areas.

Breaking down the prefecture IOTs into those of several small areas and the integration of the small area IOTs into one MRIOT may make it possible to solve the analytical problem that a region identified in terms of economic activity is not necessarily the same as the administrative region.

Nagoya is the third largest metropolitan area in Japan, following Tokyo and Osaka. Nagoya City, the capital city of Aichi Prefecture, is the economic center of the Tokai Region. However, each surrounding area is not equally connected to Nagoya City. Generally speaking, the closer the distance between areas, the stronger their economic connection. Thus, using the MRIOT for the Tokai Region, we investigate such relations by the Average Propagation Lengths (APL) index proposed by Dietzenbacher et al. (2005).

In Section 2, the related preceding studies in Japan are briefly discussed. Then in Section 3, we introduce a method to recompile our MRIOT of the Tokai Region. Section 4 discusses the structural characteristics of the Tokai Region, and in Section 5, the characteristics of the Nagoya metropolitan area are examined in terms of the APL index. Finally, Section 6 provides concluding remarks. 


\section{Background}

In Japan, there are several MRIOTs-based prefecture tables. Table 1 shows the typical experiences related to such issues in three groups. The first one is the inter-prefectural MRIOTs for specific regions in Japan, which includes Kansai Region MRIOT (Kansai Institute for Social and Economic Research (2008)), Tohoku Region MRIOT (Tohoku Region Advancement Center (2011)), Tokai Region MRIOT (Yamada (2010)), and

Table 1 Multi-regional input output tables in Japan

\begin{tabular}{|c|c|c|c|c|}
\hline Types of RIO & Authors & Table name & Sectors & Estimation of commodity flow \\
\hline \multirow{5}{*}{$\begin{array}{l}\text { 1) Inter-prefectural } \\
\text { MRIOT for the } \\
\text { specific region } \\
\text { within Japan }\end{array}$} & $\begin{array}{l}\text { Kansai Institute for } \\
\text { Social and Economic } \\
\text { Research (2008) }\end{array}$ & $\begin{array}{l}2000 \text { Kansai } \\
\text { Interregional IOT }\end{array}$ & $\begin{array}{l}7 \text { prefectures/ } \\
100 \text { sectors }\end{array}$ & $\begin{array}{l}\text { Special survey data on } \\
\text { commodity flow (METI) }\end{array}$ \\
\hline & $\begin{array}{l}\text { Asia Pacific Institute } \\
\text { of Research (2012) }\end{array}$ & $\begin{array}{l}2005 \text { Kansai } \\
\text { Interregional IOT }\end{array}$ & $\begin{array}{l}7 \text { prefectures/ } \\
104 \text { sectors }\end{array}$ & $\begin{array}{l}\text { RAS method with the survey } \\
\text { statistics of domestic net } \\
\text { freight flows (MLIT) and } \\
\text { employees' commuting flow of } \\
\text { the Census (MIC), and others }\end{array}$ \\
\hline & $\begin{array}{l}\text { Tohoku Region } \\
\text { Advancement } \\
\text { Center (2011) }\end{array}$ & $\begin{array}{l}2005 \text { Tohoku } \\
\text { Region MRIOT }\end{array}$ & $\begin{array}{l}6 \text { prefectures/ } \\
43 \text { sectors }\end{array}$ & $\begin{array}{l}\text { Special survey data on } \\
\text { commodity flow (METI) }\end{array}$ \\
\hline & Yamada (2010) & $\begin{array}{l}2000 \text { Tokai Region } \\
\text { MRIOT }\end{array}$ & $\begin{array}{l}3 \text { prefectures/ } \\
185 \text { sectors }\end{array}$ & $\begin{array}{l}\text { RAS method with the special } \\
\text { survey data of commodity } \\
\text { flow (METI) }\end{array}$ \\
\hline & $\begin{array}{l}\text { Chubu Regional } \\
\text { Institute for Social } \\
\text { and Economic } \\
\text { Research (2011) }\end{array}$ & $\begin{array}{l}2005 \text { Chubu } \\
\text { Region MRIOT }\end{array}$ & $\begin{array}{l}10 \text { prefectures/ } \\
95 \text { sectors }\end{array}$ & $\begin{array}{l}\text { RAS method with the survey } \\
\text { statistics of domestic net } \\
\text { freight flows (MLIT) }\end{array}$ \\
\hline \multirow[t]{3}{*}{$\begin{array}{l}\text { 2) Inter-prefectural } \\
\text { MRIOT covering } \\
\text { Japan overall }\end{array}$} & $\begin{array}{l}\text { Ishikawa and } \\
\text { Miyagi (2003) }\end{array}$ & $\begin{array}{l}1995 \text { MRIOT for } \\
\text { Japan }\end{array}$ & $\begin{array}{l}47 \text { prefectures/ } \\
45 \text { sectors }\end{array}$ & $\begin{array}{l}\text { RAS method with the survey } \\
\text { statistics of domestic net } \\
\text { freight flows (MLIT) }\end{array}$ \\
\hline & Hitomi (2008) & $\begin{array}{l}2000 \text { MRIOT for } \\
\text { Japan }\end{array}$ & $\begin{array}{l}47 \text { prefectures/ } \\
59 \text { sectors }\end{array}$ & $\begin{array}{l}\text { Gravity model using the freight } \\
\text { flow data of MLIT and the } \\
\text { commodity flow data of METI }\end{array}$ \\
\hline & Hagiwara (2012) & $\begin{array}{l}\text { 1990-2000-2005- } \\
\text { linked MRIOT }\end{array}$ & $\begin{array}{l}47 \text { prefectures/ } \\
59 \text { sectors }\end{array}$ & $\begin{array}{l}\text { Extended-RAS method with } \\
\text { the net freight flow of MLIT, } \\
\text { employees' commuting flow } \\
\text { of the Census, and the } \\
\text { communication traffic data } \\
\text { of MIC }\end{array}$ \\
\hline \multirow[t]{7}{*}{$\begin{array}{l}\text { 3) Intra-prefectural } \\
\text { MRIOT for the } \\
\text { specific prefecture }\end{array}$} & Tsubouchi (1991) & $\begin{array}{l}1988 \text { multi- } \\
\text { regional IOT of } \\
\text { Ehime Prefecture }\end{array}$ & $\begin{array}{l}6 \text { areas } / 50 \\
\text { sectors }\end{array}$ & $\begin{array}{l}\text { Special survey data on the } \\
\text { commodity flow in Ehime }\end{array}$ \\
\hline & Takahata (1992) & $\begin{array}{l}1985 \text { multi- } \\
\text { regional IOT of } \\
\text { Hokkaido } \\
\text { Prefecture }\end{array}$ & $\begin{array}{l}4 \text { areas } / 61 \\
\text { sectors }\end{array}$ & $\begin{array}{l}\text { Statistics on the freight flow } \\
\text { and passenger flow }\end{array}$ \\
\hline & Yamada (1996) & $\begin{array}{l}1985 \text { Mie } \\
\text { Prefecture MRIOT }\end{array}$ & $\begin{array}{l}5 \text { areas } / 84 \\
\text { sectors }\end{array}$ & $\begin{array}{l}\text { RAS method with the survey } \\
\text { data of freight flows }\end{array}$ \\
\hline & Ishikawa (2004) & $\begin{array}{l}1995 \text { Aichi } \\
\text { Prefecture MRIOT }\end{array}$ & $\begin{array}{l}3 \text { areas } / 46 \\
\text { sectors }\end{array}$ & Location Quotient (LQ) method \\
\hline & $\begin{array}{l}\text { Nakano and } \\
\text { Nishimura (2007) }\end{array}$ & $\begin{array}{l}2000 \text { MRIOT for } \\
\text { Aichi Prefecture }\end{array}$ & $\begin{array}{l}3 \text { areas/46 } \\
\text { sectors }\end{array}$ & $\begin{array}{l}\text { Gravity model estimated using } \\
\text { the commodity flows of METI } \\
\text { MRIOT }\end{array}$ \\
\hline & Nomura et al. (2011) & $\begin{array}{l}2000 \text { a MRIOT for } \\
\text { Yamaguchi } \\
\text { Prefecture }\end{array}$ & $\begin{array}{l}3 \text { areas/104 } \\
\text { sectors }\end{array}$ & Location Quotient (LQ) method \\
\hline & $\begin{array}{l}\text { Yamada and Owaki } \\
\text { (2012), Yamada (2013) }\end{array}$ & $\begin{array}{l}2005 \text { Aichi } \\
\text { Prefecture MRIOT }\end{array}$ & $\begin{array}{l}4 \text { areas/186 } \\
\text { sectors }\end{array}$ & Gravity-RAS method \\
\hline
\end{tabular}


Chubu Region MRIOT (Chubu Regional Institute for Social and Economic Research (2011)). These tables were made to investigate some particular region in Japan, and their sector size is commonly about 90 . The commodity flows between prefectures were estimated essentially by the RAS method with different statistical sources for the initial values.

The second group is the inter-prefectural MRIOT covering overall the 47 prefectures in Japan, including Ishikawa and Miyagi (2003) for the 1995 Table, Hitomi (2008) for the 2000 Table, and Hagiwara (2012) for the 1990-2000-2005-linked MRIOT. Because the number of prefectures has increased, the sector size was decreased to around 50 . The estimation of commodity flows among prefectures also depends on the RAS method. As the initial values of the RAS method, the authors used the data of survey statistics of domestic net freight flows (MLIT ${ }^{1}$ ), the commodity flow data of METI, ${ }^{2}$ employees' commuting flow of the Census, and the communication traffic data of MIC. ${ }^{3}$

The third group is the intra-prefectural MRIOT for the specific prefecture. The Ehime Prefecture MRIOT (Tsubouchi (1991)), Hokkaido Prefecture MRIOT (Takahata (1992)), and Mie Prefecture MRIOT (Yamada (1996)) were the pioneering studies. After 2000, several new studies appeared such as the 1995 Aichi MRIOT (Ishikawa (2004)), 2000 Aichi Prefecture MRIOT (Nakano and Nishimura (2007)), Yamaguchi Prefecture MRIOT (Nomura et al. (2011)), and 2005 Aichi Prefecture MRIOT (Yamada and Owaki (2012) and Yamada (2013)).

For the estimation of commodity flows within a prefecture, the pioneering works depended on the statistics regarding the freight flow and passenger flow within the prefecture, or on special surveys conducted on the commodity flow of the goods produced if there were no statistics for flows within the prefecture. In the case of Mie Prefecture, Yamada (1996) applied the RAS method with the survey data of freight flow as the initial values of the iterations. Nakano and Nishimura (2007) applied the gravity model. Ishikawa (2004) and Nomura et al. (2011) used the Location Quotient (LQ) method, which estimates the net transaction between two areas by the relative advantage measures. ${ }^{4}$ Yamada (2013) developed the Gravity-RAS method, in which a gravity model was used to obtain initial values of the RAS iterations.

Here we extend the IOT to cover the three prefectures of Aichi, Gifu, and Mie (see Fig. 1). This is called the Tokai Region, whose core city is Nagoya. Using this IOT with 14 areas and 186 sectors for each area, we are going to investigate the economic structure of the Nagoya metropolitan area, which is included in the Tokai Region. How close each area is to Nagoya City is to be discussed.

Table 2 shows the area and population of the Tokai Region. More than 11 million persons live in this region. The population of Nagoya City itself is 2.2 million, and it has the highest population density, about 6900 persons per square $\mathrm{km}$ in this region. Owari surrounding Nagoya City has the second highest density, about 2000 persons per square $\mathrm{km}$. In Gifu Prefecture, the Gifu City area has the highest density, 814 persons per square km, and the Hokusei area has 759 persons per square $\mathrm{km}$ in Mie Prefecture.

\section{Construction of a multi-regional input-output table}

In this section, we explain the outline to construct a multi-regional IOT of the Tokai Region, which consists of three prefectures; Aichi, Gifu, and Mie. First, each prefecture's table is divided into several areas' IOT of 186 sectors. These tables are imperfect in the sense that they include intra-prefectural transaction as net values. Second, we 


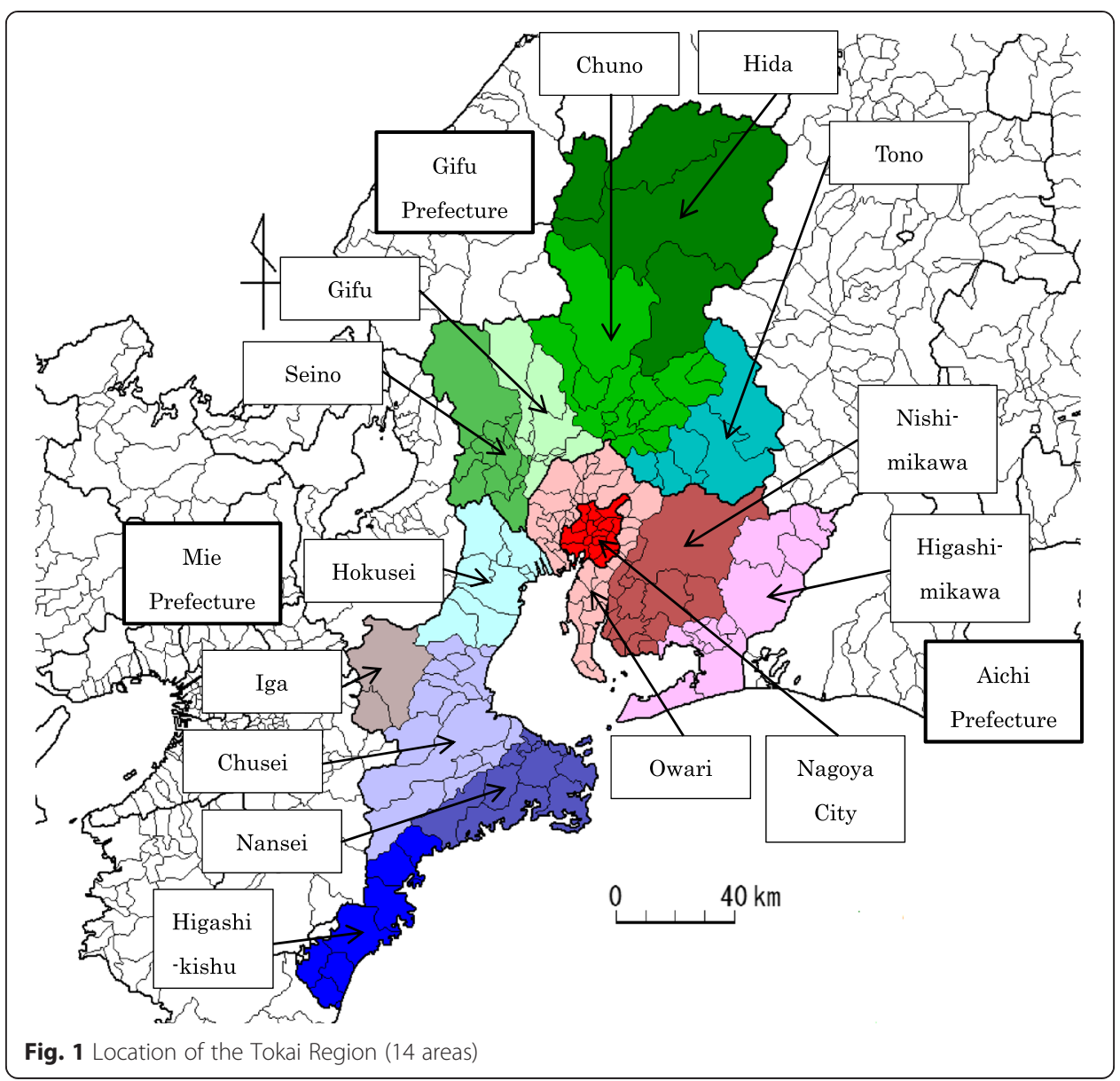

estimate the transaction values of commodity flows among the areas in two steps; the transactions within each prefecture, and the transactions among areas of different prefectures. The two-stepwise estimations are adopted for the consistency with the domestic trade of each prefecture's table.

\subsection{Regional decomposition of each prefecture's IOT}

Here we explain the method to divide a prefecture's IOT into several IOTs of the smaller areas.

1) Output values

The output values of each smaller area are estimated by multiplying the appropriate ratio to the prefecture's value by sector as follows:

$X_{i}^{s}=r_{i}^{s} X_{i}$,

where $X_{i}^{s}$ is the output value of the $i$ th sector in the $s$ th area, $r_{i}^{s}$ denotes the dividing index of the $i$ th sector in the $s$ th area, and $X_{i}$ means the output value of the $i$ th sector in a given prefecture. In the manufacturing sectors, for example, the product values of each municipal are added to that of each area, the area's share of which is used as the dividing index. 
Table 2 Area and population of the Tokai Region

\begin{tabular}{|c|c|c|c|c|c|}
\hline & \multirow{2}{*}{$\begin{array}{l}\text { Area } \\
\mathrm{km}^{2}\end{array}$} & \multirow{2}{*}{$\begin{array}{l}\text { Population in } 2005 \\
\text { Thousand }\end{array}$} & \multirow{2}{*}{$\begin{array}{l}\text { Population in } 2010 \\
\text { Thousand }\end{array}$} & \multirow{2}{*}{$\begin{array}{l}\text { Population density in } 2010 \\
\text { Person } / \mathrm{km}^{2}\end{array}$} \\
\hline & & & & & \\
\hline \multicolumn{2}{|c|}{ Aichi Prefecture } & 5163.9 & 7254.7 & 7410.7 & 1435.1 \\
\hline 1 & Nagoya & 326.4 & 2215.1 & 2263.9 & 6935.3 \\
\hline 2 & Owari & 1393.0 & 2806.9 & 2875.2 & 2064.0 \\
\hline 3 & Nishi-mikawa & 1724.5 & 1466.0 & 1506.0 & 873.3 \\
\hline 4 & Higashi-mikawa & 1720.0 & 766.8 & 765.7 & 445.2 \\
\hline \multicolumn{2}{|c|}{ Gifu Prefecture } & $10,621.2$ & 2107.2 & 2080.8 & 195.9 \\
\hline 5 & Gifu & 992.5 & 802.2 & 807.6 & 813.6 \\
\hline 6 & Seno & 1433.4 & 391.6 & 385.0 & 268.6 \\
\hline 7 & Chuno & 2454.9 & 388.9 & 382.6 & 155.8 \\
\hline 8 & Tono & 1562.8 & 358.9 & 348.1 & 222.7 \\
\hline 9 & Hida & 4177.6 & 165.6 & 157.5 & 37.7 \\
\hline \multicolumn{2}{|c|}{ Mie Prefecture } & 5777.3 & 1867.0 & 1854.7 & 321.0 \\
\hline 10 & Hokusei & 1107.3 & 823.6 & 840.2 & 758.7 \\
\hline 11 & Chusei & 1841.6 & 507.0 & 502.5 & 272.8 \\
\hline 12 & Nansei & 1148.7 & 267.7 & 255.0 & 222.0 \\
\hline 13 & Iga & 687.9 & 182.8 & 177.5 & 258.0 \\
\hline 14 & Higashi-kishu & 991.7 & 85.8 & 79.6 & 80.2 \\
\hline \multicolumn{2}{|c|}{ Tokai Region } & $21,562.3$ & $11,228.9$ & $11,346.2$ & 526.2 \\
\hline
\end{tabular}

2) Intermediate input and value added

Assuming that the inputs coefficient and value-added ratios to the outputs are same for each area within the prefecture, the intermediate input values and value added of each sector are estimated as follows:

$X_{i j}^{s}=a_{i j} X_{i}^{s}$

$V_{i j}^{s}=v_{i j} X_{i}^{s}$

where $X_{i j}^{s}$ is the intermediate input of the $i$ th commodity for the $j$ th sector in the $s$ th area, $a_{i j}$ denotes the input coefficient of the $i$ th commodity for the $j$ th sector in the prefecture, $V_{i j}^{s}$ means the $i$ th value added of the $j$ th sector in the $s$ th area, and $v_{i j}$ is the $i$ th value added ratio of the $j$ th sector in the prefecture.

3) Domestic final demand

The domestic final demand consists of private consumption, ${ }^{5}$ government consumption, private investment, public investment, and change of inventory.

The private consumption of each area is estimated by multiplying the appropriate ratio to the prefecture's value by sector as follows:

$C_{i}^{s}=\gamma_{i}^{s} C_{i}$

where $C_{i}^{s}$ is the consumption of the $i$ th commodity in the $s$ th area, and $\gamma_{i}^{s}$ denotes the dividing index of the $i$ th sector in the $s$ th area, and $C_{i}$ means the consumption of the $i$ th commodity in the prefecture. The dividing factor is estimated as follows:

$\gamma_{i j}^{s}=c_{i 1} n_{j 1}^{s}+c_{i 2} n_{j 2}^{s}$, 
where $c_{i 1}$ and $c_{i 2}$ are the consumptions for each household of the $i$ th commodity in the prefecture, for two-or-more-person households and one-person households, respectively, which are obtained from the National Survey of Family Income and Expenditure, MIC. $n_{j 1}^{s}$ and $n_{j 2}^{s}$ means the number of households; two-or-more-person and one-person, respectively.

The estimation of government consumption, private investment, and public investment is conducted in almost the same way so as to divide them into those of the areas by using the appropriate dividing shares.

The change of inventory is estimated assuming that the inventory change's ratio to the output in an area is the same in the prefecture.

$J_{i}^{s}=\left(J_{i} / X_{i}\right) X_{i}^{s}$

where $J_{i}^{s}$ is the inventory change of the $i$ th sector in the $s$ th area, and $J_{i}$ is the corresponding value of the prefecture.

4) International trade

Here we must estimate the export and import values for each small area. We assume that the export ratio to the output for each sector is the same within the prefecture. Then the export for each area is reduced as follows:

$E_{i}^{s}=e_{i} X_{i}^{s}$,

where $E_{i}^{s}$ means the export of the $i$ th commodity in the $s$ th area, and $e_{i}$ denotes the export ratio to output by sector in the prefecture, that is $e_{i}=E_{i} / X_{i}$. Here $E_{i}$ is the export of the $i$ th sector in the prefecture.

Assuming that the import coefficient for each area is the same within the prefecture, the import of the area is reduced as follows:

$M_{i}^{s}=m_{i} D_{i}^{s}$,

where $M_{i}^{s}$ means the import of the $i$ th commodity in the $s$ th area, $m_{i}$ denotes the import coefficient by sector in the prefecture, and $D_{i}^{s}$ shows the domestic demand of the $i$ th commodity in the $s$ th area. The import coefficient of the prefecture is defined as $m_{i}=M_{i} / D_{i}$, where $M_{i}$ is the import of the $i$ th sector and $D_{i}$ is the domestic demand of the $i$ th sector in the prefecture.

5) Internal trade with outside of the prefecture

We estimate the export and import values with the rest of Japan for each area. Assuming that the export ratio to the output for each sector is the same for the internal trade with the rest of Japan, the export for each area is reduced as follows:

$E_{i}^{* s}=e_{i}^{*} X_{i}^{s}$,

where $E_{i}^{* s}$ means the $i$ th commodity's export to the rest of Japan in the $s$ th area, and $e_{i}^{*}$ denotes the corresponding export ratio to output by sector in the prefecture, $e_{i}^{*}=E_{i}^{*} / X_{i}$. Here $E_{i}^{*}$ is the export of the $i$ th sector in the prefecture.

For the import, we assume that the import coefficient from the rest of Japan is the same for each area within the prefecture. Then the import of the area is reduced as follows:

$M_{i}^{* s}=m_{i}^{*} D_{i}^{s}$, 
where $M_{i}^{* s}$ means the $i$ th commodity's import in the $s$ th area, and $m_{i}^{*}$ denotes the import coefficient by sector in the prefecture. The import coefficient of the prefecture is defined as $m_{i}^{*}=M_{i}^{*} / D_{i}$, where $M_{i}^{*}$ is the $i$ th commodity's import from the rest of Japan.

6) Balancing equation

After estimating each item by sector, the total demand must be equal to the total supply. Then the following equation holds for each sector in each area:

$D_{i}^{s}+E_{i}^{s}+E_{i}^{* s}-M_{i}^{s}-M_{i}^{* s}+\Delta N_{i}^{s}=X_{i}^{s}$,

where $D_{i}^{s}=\sum X_{i j}^{s}+F_{i}^{s}$.

Here $D_{i}^{s}$ denotes the total domestic demand of the $i$ th commodity in the $s$ th area, which consists of the intermediate demands $\sum X_{i j}^{s}$ and the final demand, $F_{i}^{s}$. The variable $\Delta N_{i}^{R}$ means the net export to the other areas within the prefecture, which works as the balancing factor after estimating all the other items independently.

\subsection{Estimation of commodity flows between areas}

Here we use the gravity-RAS method by which the estimates from the gravity model are used as the initial values for the RAS iterations to obtain the commodity flow among areas.

Table 3 shows the illustrative flows of the $i$ th commodity among four areas, two of which are included in each of two prefectures, respectively. ${ }^{6}$ Two regions, the rest of Japan and the rest of the world, appear in the table to capture the domestic and international transactions. $T_{i}^{r s}$ shows the transaction of the $i$ th commodity from the $r$ th area to the $s$ th area, $T_{i}^{r}$ denotes the total values of transaction of the $i$ th commodity from the $r$ th area, and $T_{i}^{s}$ means the total values of transaction of the $i$ th commodity to the $s$ th area. $E_{i}^{s}$ and $M_{i}^{s}$ are respective exports and imports to and from the world, and $E_{i}^{* s o}$ and $M_{i}^{* o s}$ are exports and imports to and from the rest of Japan, which is defined as the region excluding the two prefectures in Japan in this case.

The following equations must be considered.

$$
\begin{aligned}
& \sum_{s} T_{i}^{r s}+E_{i}^{* r o}+E_{i}^{r}=T_{i}^{r} \text { for } r=1,2,3, \text { and } 4, \\
& \sum_{r} T_{i}^{r s}+M_{i}^{* o s}+M_{i}^{s}=T_{i}^{\cdot s} \text { for } s=1,2,3, \text { and } 4 .
\end{aligned}
$$

Table 3 Interregional flows of the ith commodity

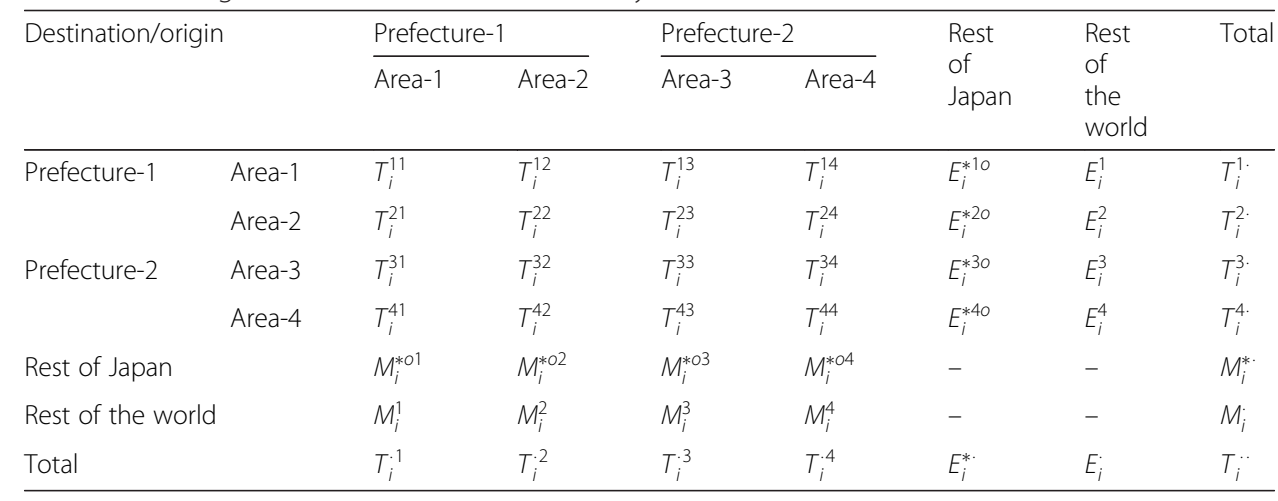


In this table, the values of the following variables are known from each of the decomposed IOTs.

1) Export $E_{i}^{s}$ and import $M_{i}^{s}$ are known for $s=1,2,3$, and 4.

2) Domestic transaction $E_{i}^{* s}$ and $M_{i}^{* s}$ with the rest of Japan are known with the relations,

Prefecture-1 : $\quad \sum_{s \neq 1} T_{i}^{r s}+E_{i}^{* r o}=E_{i}^{* r}$ for $r=1,2$

Prefecture-2: $\quad \sum_{s \neq 2} T_{i}^{r s}+E_{i}^{* r o}=E_{i}^{* r}$ for $r=3,4$.

3) The total value supplied from the $r$ th area to all areas and regions $T_{i}^{r}$ is equal to the output of the area $X_{i}^{r}$, and the total value received from all areas and regions to the $r$ th area $T_{i}^{\cdot s}$ is same as the total demand of the $s$ th area, $D_{i}^{s}$, that is,

$T_{i}^{r \cdot}=X_{i}^{r}$,

$T_{i}^{s}=D_{i}^{s}$.

Here, $X_{i}^{r}$ and $D_{i}^{s}$ are obviously obtained from the divided IOT.

Considering the above restrictions, we must determine the transaction values $T_{i}^{r s}$ in an appropriate way. To solve this model, we use a two-step estimation strategy that distinguishes the intra-prefectural transaction from the transactions between prefectures in the estimation.

\subsubsection{Estimation of intra-prefectural flows}

Table 4 shows the intra-prefectural flows of the $i$ th commodity, and the row-sum values and column-sum values are obtained from each decomposed IOT. Holding the following equations, we are able to determine the values of intra-prefectural transaction $T_{i}^{r s}$.

$$
\begin{aligned}
& \sum_{s=1,2 / 3,4} T_{i}^{r s}=X_{i}^{r}-E_{i}^{* r}-E_{i}^{r} \\
& \sum_{r=1,2 / 3,4} T_{i}^{r s}=D_{i}^{s}-M_{i}^{* s}-M_{i}^{s}
\end{aligned}
$$

Then we apply the RAS method with appropriate initial values. In this table, we apply the gravity model, which is to be explained in Section 3.2.3, to obtain the initial values.

\begin{tabular}{|c|c|c|c|c|c|c|}
\hline \multicolumn{2}{|c|}{ Destination/origin } & \multicolumn{2}{|l|}{ Prefecture-1 } & \multicolumn{2}{|l|}{ Prefecture-2 } & \multirow[t]{2}{*}{ Total } \\
\hline & & Area-1 & Area-2 & Area-3 & Area-4 & \\
\hline \multirow[t]{2}{*}{ Prefecture-1 } & Area-1 & $T_{i}^{11}$ & $T_{i}^{12}$ & - & - & $\overline{X_{i}^{1}-E_{i}^{* 1}-E_{i}^{1}}$ \\
\hline & Area-2 & $T_{i}^{21}$ & $T_{i}^{22}$ & - & - & $X_{i}^{1}-E_{i}^{* 1}-E_{i}^{1}$ \\
\hline \multirow[t]{2}{*}{ Prefecture-2 } & Area-3 & - & - & $T_{i}^{33}$ & $T_{i}^{34}$ & $X_{i}^{3}-E_{i}^{* 3}-E_{i}^{3}$ \\
\hline & Area-4 & - & - & $T_{i}^{43}$ & $T_{i}^{44}$ & $X_{i}^{4}-E_{i}^{* 4}-E_{i}^{4}$ \\
\hline \multicolumn{2}{|l|}{ Total } & $D_{i}^{1}-M_{i}^{* 1}-M_{i}^{1}$ & $D_{i}^{2}-M_{i}^{* 2}-M_{i}^{2}$ & $D_{i}^{3}-M_{i}^{* 3}-M_{i}^{3}$ & $D_{i}^{4}-M_{i}^{* 4}-M_{i}^{4}$ & \\
\hline
\end{tabular}

Table 4 Intra-prefectural flows of the ith commodity 


\subsubsection{Estimation of inter-prefectural flows}

After estimating the intra-regional commodity flows, we must determine the values of inter-prefectural commodity flows, as shown in Table 5.

In the following equations, both exports and imports to and from the region outside of both prefectures $E_{i}^{* r o}$ and $M_{i}^{* o s}$ are not known, though exports and imports with the rest of Japan, $E_{i}^{* r}$ and $M_{i}^{* s}$, are obtained from the IOT.

$$
\begin{aligned}
& \sum_{s=1,2 / 3,4} T_{i}^{r s}=E_{i}^{* r}-E_{i}^{* r o} \\
& \sum_{r=1,2 / 3,4} T_{i}^{r s}=M_{i}^{* s}-M_{i}^{* o s}
\end{aligned}
$$

To obtain their values, we multiply the predicted share by the gravity model to the total values as follows:

$$
\begin{aligned}
& \hat{E}_{i}^{* r o}=\frac{\hat{E}_{i}^{* r o}}{\sum_{s} \hat{T}_{i}^{r s}+\hat{E}_{i}^{* r o}} E_{i}^{* r}, \\
& \hat{M}_{i}^{* o s}=\frac{\hat{M}_{i}^{* o s}}{\sum_{r} \hat{T}_{i}^{r s}+\hat{M}_{i}^{* o s}} M_{i}^{* s},
\end{aligned}
$$

where the variables with hats denote the predicted ones by the gravity model with some modification to fulfill the condition that the sum of the "total" column is equal to that of the "total" row. ${ }^{7}$ This condition means that the sum of the exports within prefectures concerned is equal to the sum of the imports within the same prefectures. Here we apply the gravity-RAS method to obtain the transaction values $T_{i}^{r s}$, that keep the condition expressed by Eqs. (9) and (10), within the concerned prefectures.

\subsubsection{The modified gravity model}

The gravity model shows that the volume of transactions from region $r$ to region $s T_{i}^{r s}$ is proportionally related to the total volumes of both the origin $T_{i}^{r}$ and the destination $T_{i}^{\cdot s}$ and disproportionally to the distance between the regions ${ }^{8} \bar{L}^{r s}$ as follows:

$$
T_{i}^{r s}=k_{i}^{r s} \frac{\left(T_{i}^{r \cdot}\right)^{\alpha}\left(T_{i}^{\cdot s}\right)^{\beta}}{\left(\bar{L}^{r s}\right)^{\gamma}}
$$

where $\alpha, \beta$, and $\gamma$ are parameters of the two volume variables and distance variable,

\begin{tabular}{|c|c|c|c|c|c|c|}
\hline \multicolumn{2}{|c|}{ Destination/origin } & \multicolumn{2}{|c|}{ Prefecture-1 } & \multicolumn{2}{|c|}{ Prefecture-2 } & \multirow[t]{2}{*}{ Total } \\
\hline & & Area-1 & Area-2 & Area-3 & Area-4 & \\
\hline \multirow[t]{2}{*}{ Prefecture-1 } & Area-1 & - & - & $T_{i}^{13}$ & $T_{i}^{14}$ & $\overline{E_{i}^{* 1}-E_{i}^{* 10}}$ \\
\hline & Area-2 & - & - & $T_{i}^{23}$ & $T_{i}^{24}$ & $E_{i}^{* 2}-E_{i}^{* 20}$ \\
\hline \multirow[t]{2}{*}{ Prefecture-2 } & Area-3 & $T_{i}^{31}$ & $T_{i}^{32}$ & - & - & $E_{i}^{* 3}-E_{i}^{* 30}$ \\
\hline & Area-4 & $T_{i}^{41}$ & $T_{i}^{42}$ & - & - & $E_{i}^{* 4}-E_{i}^{* 40}$ \\
\hline \multicolumn{2}{|l|}{ Total } & $M_{i}^{* 1}-M_{i}^{* 0}$ & $M_{i}^{* 2}-M_{i}^{* 02}$ & $M_{i}^{* 3}-M_{i}^{* 03}$ & $M_{i}^{* 4}-M_{i}^{* 04}$ & \\
\hline
\end{tabular}
respectively. Taking the logarithm on both sides of Eq. (13), the parameters are estimated from the transaction data among 9 regions of the 2005 METI MRIOT for each of 186 sectors. Because some sectors have no transaction with the other regions, 153

Table $\mathbf{5}$ Inter-prefectural flows of the ith commodity 
sectors are estimated. Generally speaking, the transactions within each region are not included in the gravity model. However, we estimated the model with the transaction data not only between regions but also within each region, because we needed some estimates for the transaction within regions.

Table 6 describes the characteristics of the estimated parameters. Almost all of the parameters are estimated to be statistically significant. The average values of the volume parameters for the origin and the destination are 0.99 and 0.74 , respectively. The average of distance parameters is 1.29 . The distance average of the commodity sectors is 1.12, which is lower than that of the service sectors, 1.77, as expected. Figure 2 shows the distribution of each estimated parameter. We are able to confirm that the distance parameters are scattered wider than the two volume parameters, and that distance parameters of service sectors are more widely dispersed than those of commodity sectors.

For our purpose, we applied the gravity model asymptotically to induce the transaction coefficients $\hat{t}_{i}^{r s}$ between areas of our IOT, and the estimates were used as initial values for the RAS iterative method to estimate the transaction values $T_{i}^{r s}$.

$$
\begin{aligned}
& \hat{t}_{i}^{r s}=\frac{\hat{T}_{i}^{r s}}{\sum_{r} \hat{T}_{i}^{r s}}, \\
& \hat{T}_{i}^{r s}=\hat{k}_{i}^{r s} \frac{\left(\hat{T}_{i}^{r \cdot}\right)^{\hat{\alpha}}\left(\hat{T}_{i}^{s}\right)^{\hat{\beta}}}{\left(\hat{\bar{L}}^{r s}\right)^{\hat{\gamma}}}
\end{aligned}
$$

where $\hat{\alpha}, \hat{\beta}, \hat{\gamma}$, and $\hat{k}_{i}^{r s}$ are the estimated parameters. The variables $\hat{T}_{i}^{r}, \hat{T}_{i}^{s}$, and $\hat{\bar{L}}^{r s}$ are values corresponding to the MRIOT compiled here.

Additional file 1 shows the estimated transaction matrix among areas for all commodities. In this table, there are exports and imports, international and domestic, of the Tokai region. The export shares and import shares are also calculated. The shadow cells mean the areas whose transaction share has amounts to $5 \%$ and more. Looking at these shares, we note that four areas in Aichi Prefecture have strong relations among them. Also there appears to be strong interdependence among Gifu, Seino, Chuno, and Tono areas in Gifu Prefecture, though the Hida area seems to have a slightly weak relation to them. In Mie Prefecture, the Hokusei and Chusei areas have relatively strong links.

Table 6 Characteristics of the estimated parameters

\begin{tabular}{llll}
\hline & Total volume of the origin & Total volume of the destination & Distance \\
\hline Maximum value & 1.92 & 1.27 & 3.08 \\
Minimum value & -0.02 & -0.08 & 0.20 \\
Average & 0.99 & 0.74 & 1.29 \\
$\quad$ of commodity sectors & 0.96 & 0.75 & 1.12 \\
$\quad 1.06$ & 0.70 & 1.77 \\
of service sectors & 0.28 & 0.23 & 0.57 \\
Standard deviation & 153 & 153 & 153 \\
No. of equations & 150 & 149 & 149 \\
\hline
\end{tabular}




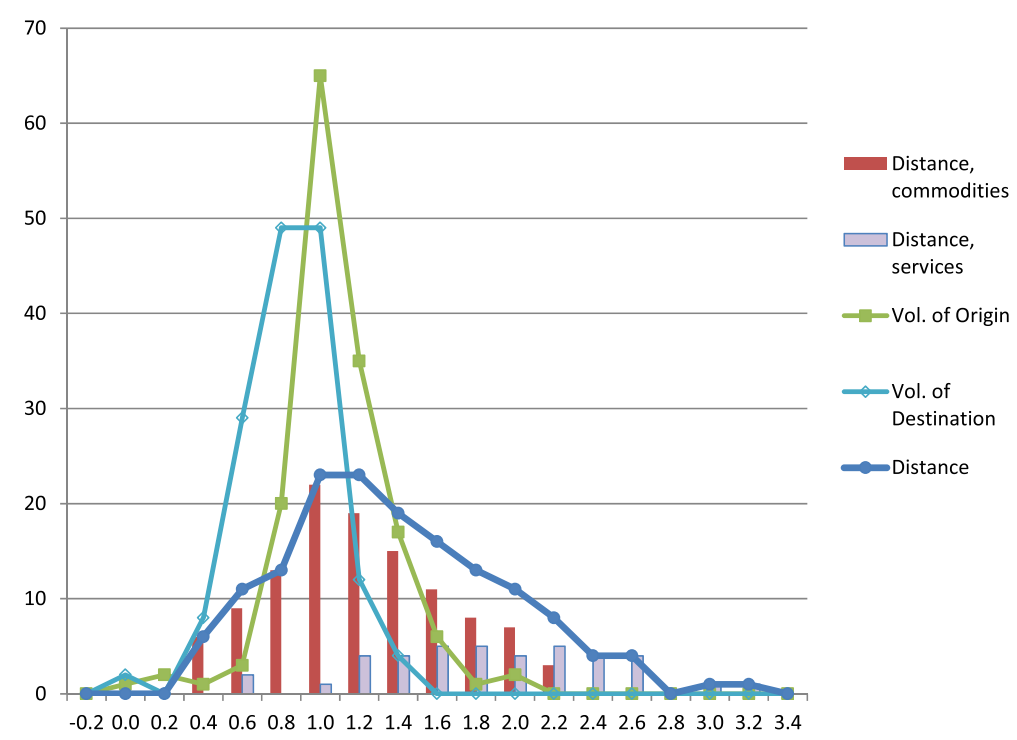

Fig. 2 Distribution of the estimated parameters

There are relatively strong relations between the Owari area in Aichi Prefecture and three areas in Gifu Prefecture; Gifu, Seino, and Chuno. The Hokusei area in Mie Prefecture and Nishi-mikawa area in Aichi Prefecture are also linked.

\subsection{The compiled multi-regional input-output table}

We divide three prefectures' IOTs with 186 sectors into 14 areas' IOTs and estimate the transaction flows among areas and the outside regions, domestic and international for each sector. Here we are able to combine the 14 tables into one multi-regional IOT using the sectoral transaction flow matrices. Additional file 2 shows the MRIOT compiled for the Tokai Region with 14 areas, in which 186 sectors are integrated into 40 sectors.

\section{Comparison of output structures}

In this section, we integrate the MRIOT with 14 areas and 186 sectors for each area to that with 14 areas and 40 sectors and discuss the characteristics of the output structures in Additional files 3, 4, and 5. Those tables contain sectoral outputs and the Revealed Comparative Advantage (RCA) indices of output in the Tokai Region.

Additional file 3 shows that Nagoya City has relative advantages in "Information and communications," "Commerce," "Finance and insurance," "Real estate," and "Business services." Those sectors are strongly related to the core industries in the metropolitan area. On the other hand, the Owari area has advantages in "Petroleum and coal products," "Pottery, china and earthenware," "Aircraft and repair of aircraft," and "Miscellaneous manufactured products." The Nishi-mikawa area, where Toyota Motor Co. is headquartered along with its factories and group companies, has advantages in "Information and communication electronics equipment," "Electronic components," and "Motor vehicles." The Higashi-mikawa area has advantages in "Agriculture," "Motor Vehicles," "Other transportation equipment," and "Precision instruments." 
Additional file 4 shows the output structures of five areas in Gifu Prefecture. The Gifu area, where the capital city of the prefecture is located, has strong industries in "Aircraft and repair of aircraft," and "Textile products." Historically, textile industries prospered in this area. The Seino area, located west of the Gifu area, has advantages in its manufacturing industries such as "Other ceramic, stone and clay products," "Metal products," "Electrical machinery," "Precision instruments," "Textile products," and "Plastic products" in addition to the "Mining." The Tono area, in eastern Gifu Prefecture, has advantages in manufacturing industries like "Pulp, paper and wood products," "Metal products," "General machinery," and "Information and communication electronics equipment," along with "Forestry." On the other hand, the Hida area, located in northern Gifu Prefecture, has much natural resources, superiority in "Forestry," "Fishery," "Mining," "Pulp, paper and wood products," and "Electricity, gas and heat supply," that is generated by hydropower stations.

Additional file 5 shows the output structures of five areas in Mie Prefecture. The Hokusei area, the northern parts of Mie Prefecture and next to the Owari area, has advantages in its "Chemical products," "Petroleum and coal products," "Iron and steel," "Non-ferrous metals," "Information and communication electronics equipment," and "Motor vehicles." Contrarily, the Chusei area, located in the central part of Mie Prefecture, has advantages in not only manufacturing industries like "Electronic components," "Miscellaneous manufactured products," and "Other ceramic, stone and clay products," but also the tertiary sectors such as "Information and communications," and "Public administration." In the Nansei area, the "Aircraft and repair of aircraft" sector is one of the competitive industries, though its production is not so large. "Fishery" also has a large sector in this area. The Iga area, deep in Mie Prefecture, is relatively close to the Kansai Region and boasts of "Pottery, china and earthenware," "Plastic products," "Pulp, paper and wood products," and "General machinery." In the Higashi-kishu area, "Forestry" and "Fishery" sectors have relative advantages, and the "Pulp, paper and wood products" sector also has relatively larger production. In this area there are thermal power plants, so the production of "Electricity, gas and heat supply" sector is also extensive.

\section{Average propagation lengths}

The Average Propagation Lengths (APL) index, proposed by Dietzenbacher et al. (2005), is used to measure the economic distances between industries. This index is defined as follows.

When we express the Leontief inverse matrix $\mathbf{L}$ for the standard Leontief quantity model is denoted as follows:

$$
\mathbf{L}=(\mathbf{I}-\mathbf{A})^{-\mathbf{1}}=\mathbf{I}+\mathbf{A}+\mathbf{A}^{2}+\mathbf{A}^{3}+\cdots
$$

where A means the input coefficient matrix of the model, the overall indirect effects are expressed as

$$
\mathbf{L}-\mathbf{I}=\mathbf{A}+\mathbf{A}^{2}+\mathbf{A}^{\mathbf{3}}+\mathbf{A}^{\mathbf{4}}+\cdots
$$

On the other hand, we can define the weighted sum of the intermediate input, with the number of each diffusion stage as the weight, as follows: 


$$
\Phi=A+2 A^{2}+3 A^{3}+4 A^{4}+\cdots=L(L-1)
$$

Then the average propagation lengths (APL) $\mathbf{A P L}_{\mathbf{i j}}$ between the $j$ th sector and the $i$ th sector in the model is defined as

$$
\mathbf{A P L}_{\mathbf{i j}}=[\mathbf{L}(\mathbf{L}-\mathbf{I})]_{\mathbf{i j}} /[\mathbf{L}-\mathbf{I}]_{\mathbf{i j}}
$$

where $[\mathbf{L}-\mathbf{I}]_{\mathbf{i j}}$ denotes the $\mathrm{i}-\mathrm{j}$ element of the matrix $\mathbf{L}-\mathbf{I}$.

Calculating the APL between the $j$ and $i$ for the model with 40 sectors for each of 14 areas, we have integrated them as the index between the $r$ th area and $s$ th area, $\mathbf{A P L} \mathbf{r s}^{\mathbf{r s}}$,

$$
\mathrm{APL}^{\mathbf{r s}}=\sum_{\mathbf{i} \in \mathbf{r}} \sum_{\mathbf{j} \in \mathbf{s}} \mathbf{v}_{\mathbf{i}}^{\mathbf{r}} \mathrm{APL}_{\mathbf{i j}} \mathbf{f}_{\mathbf{j}}^{\mathbf{s}}
$$

where $\mathbf{v}_{\mathbf{i}}^{\mathbf{r}}$ is the share vector of the value added in region $r$ and $\mathbf{f}_{\mathbf{j}}^{\mathbf{s}}$ is the share vector of the final demand in region $s$. The APL index is usually interpreted as the distance between industries, as Dietzenbacher et al. (2005) originally applied to a regional IOT. Here we are able to obtain APL with respect to the regions, and examine it as the index to measure the spatial distance. The regional comparison of the APL index appears in the analysis using the international input-output model (Dietzenbacher and Romero (2007)). However, we compare the APL with respect to areas to the geographical distance to measure the relation between the core city and the surrounding areas in the MRIOT.

Figure 3 shows the relation between the APL and the logarithm of the geographical distance. The positive relation is observed with the correlation coefficient 0.681 . The triangle points in Fig. 3 denote the APL distance of Nagoya City to the other areas in

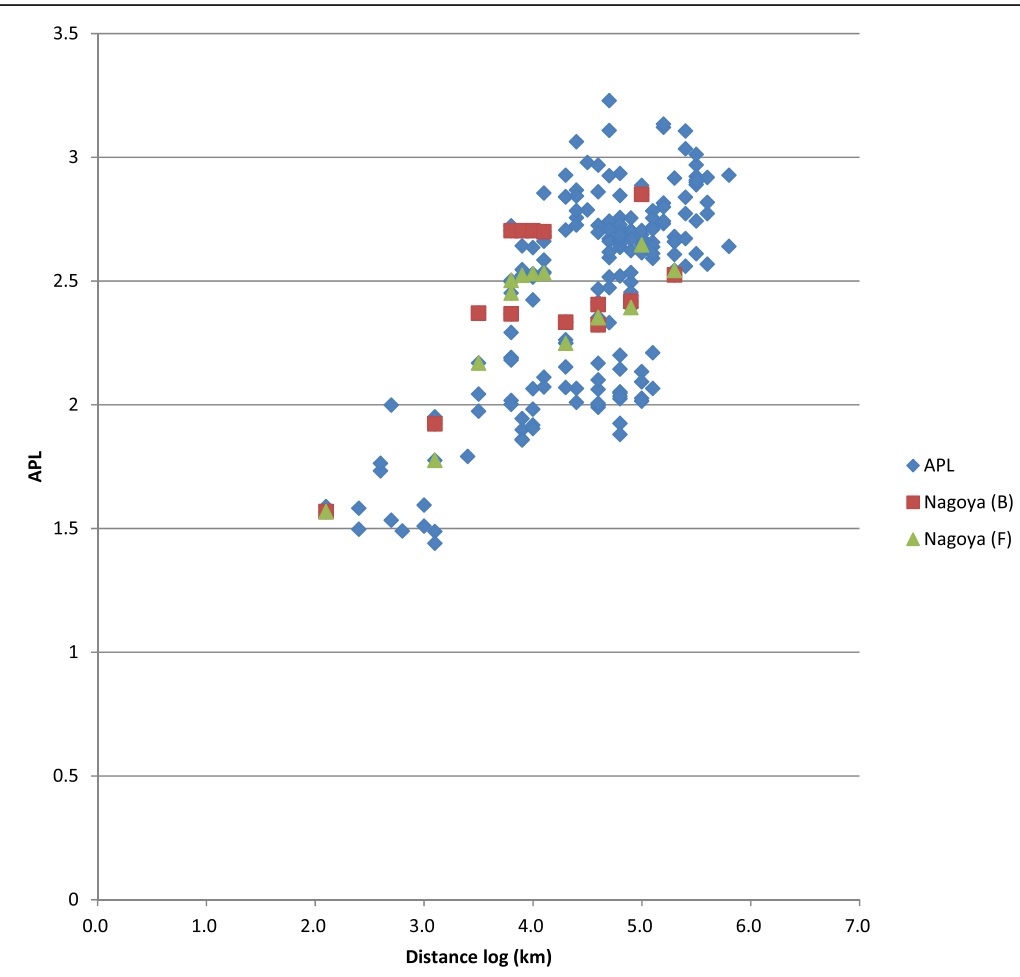

Fig. 3 Average propagation lengths and distance 
the forward direction, and the square points show them in the backward direction. Both show that the APL distance of Nagoya City becomes larger as the geographical distance becomes longer. The area closer to Nagoya City has deeper connections with the city and the transaction between them becomes larger, which makes the APL distance lower.

We estimate the regression of the APL on the logarithm of the distance with some prefectural dummies from 196 samples. The estimated equation is

$$
A P L^{r s}=\alpha+\beta \ln \left(D^{r s}\right)+\gamma_{G}^{F} D_{G}^{F}+\gamma_{G}^{B} D_{G}^{B}+\gamma_{M}^{F} D_{M}^{F}+\gamma_{M}^{B} D_{M}^{B}+\gamma_{N}^{F} D_{N}^{F}+\gamma_{N}^{B} D_{N}^{B},
$$

where $D^{r s}$ is the geographical distance between $r$ and s. $D_{G}^{F}$ and $D_{G}^{B}$ denote dummy variables of Gifu Prefecture, in the forward and backward direction, respectively. $D_{M}^{F}$ and $D_{M}^{B}$ are also dummy variables for Mie Prefecture, and $D_{N}^{F}$ and $D_{N}^{B}$ are for Nagoya City. The estimated results are shown in Table 7. The relation is significant in the sense of a relatively high determinant coefficient, 0.5706 . The APL index is positively correlated to the logarithm of the geographical distance. Among the prefectural dummy variables, the dummy of Gifu Prefecture in the forward direction is not significant, though the others are. The prefectural dummies are negative, which means that the industries of Aichi Prefecture are more closely concentrated than in the other two prefectures. Nagoya Dummy is also not significant, which means there is no difference from Aichi Prefecture.

Figure 4 shows the APL distance from Nagoya City, which is here defined as the average of two variations; the forward and backward direction:

$$
\mathbf{A P L} \mathbf{L}^{* \mathbf{r s}}=\frac{1}{2}\left(\mathbf{A P L} \mathbf{L}^{\mathbf{r s}}+\mathbf{A P L} \mathbf{L}^{\mathbf{s r}}\right)
$$

In this figure, relatively wide areas surrounding Nagoya City are linked to Nagoya City. Among them, the Hida area in Gifu Prefecture has little connection to Nagoya City. The Owari area is strongly connected to Nagoya City, and Nishi-mikawa and Higashi-mikawa in Aichi Prefecture also have connections. Chusei and Iga in Mie Prefecture also have relatively stronger linkage to Nagoya City than Hokusei, though the

Table 7 Regression result of the APL on the logarithm of the distance

\begin{tabular}{lllll}
\hline Variable & Coefficient & Standard error & t-statistic & Probability \\
\hline C & 0.907905 & 0.124932 & 7.267164 & 0.0000 \\
LOG (DISTANCE) & 0.403806 & 0.026481 & 15.24903 & 0.0000 \\
GIFUF & -0.078902 & 0.052282 & -1.509181 & 0.1329 \\
GIFUB & -0.170883 & 0.052282 & -3.268515 & 0.0013 \\
MIEF & -0.202266 & 0.052698 & -3.838196 & 0.0002 \\
MIEB & -0.280918 & 0.052698 & -5.330704 & 0.0000 \\
NAGOYAF & -0.063877 & 0.082821 & -0.771270 & 0.4415 \\
NAGOYAB & -0.029044 & 0.082821 & -0.350683 & 0.7262 \\
$R^{2}$ & 0.570567 & Adjusted $R^{2}$ & & 0.554577 \\
S.E. of regression & 0.267254 & Sum squared residuals & & 13.42782 \\
F-statistic & 35.68379 & Probability (F-statistic) & & 0.000000 \\
\hline
\end{tabular}




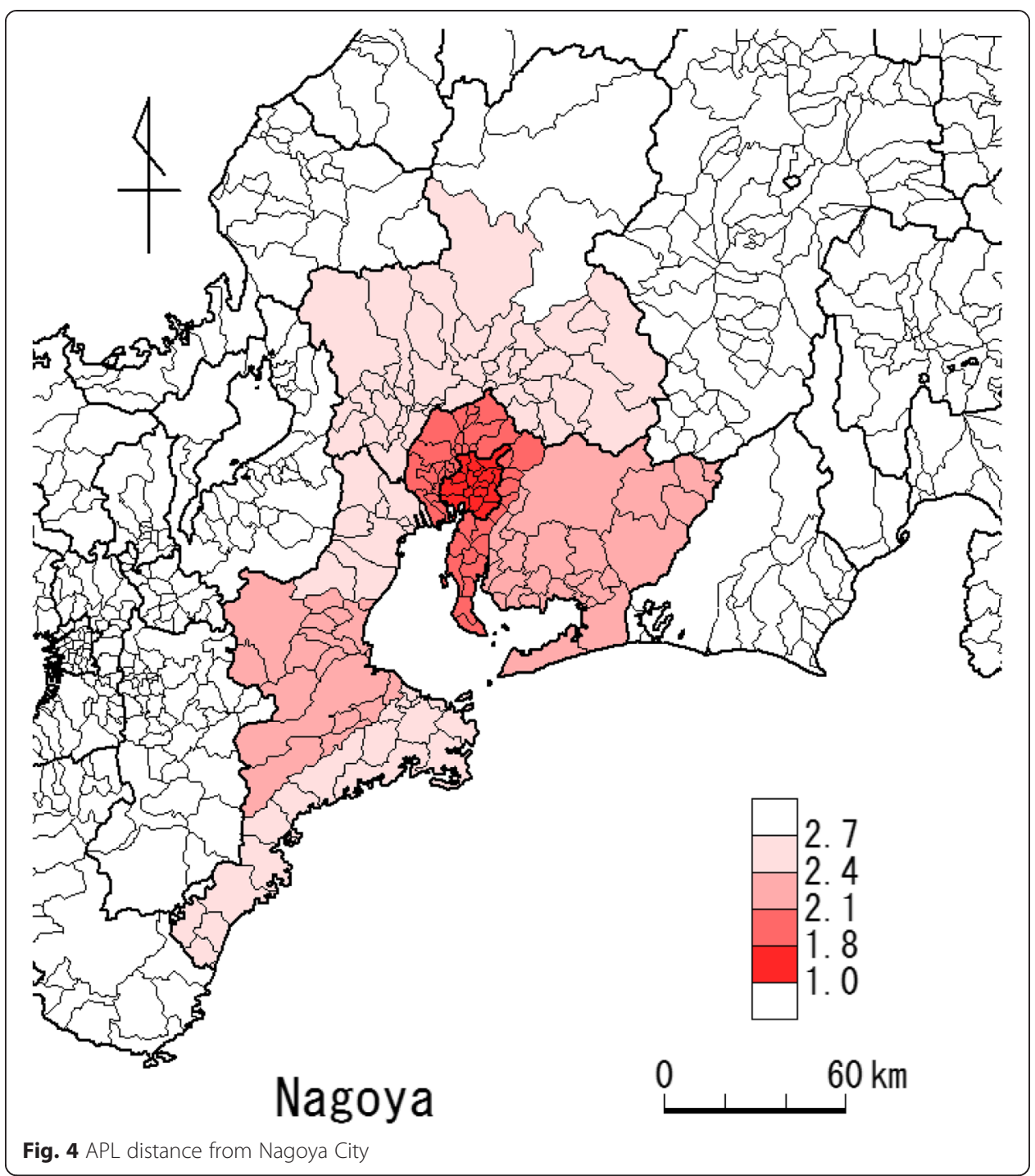

geographical distances are in reverse order. The APL index is useful to measure the degree of linkage among areas.

\section{Concluding remarks}

In this paper, we recompiled three prefectures' IOTs to a MRIOT to discuss the regional structure of the Nagoya metropolitan area. First, the original table with $186 \mathrm{sec}-$ tors for each prefecture was subdivided into a number of tables with smaller areas. Then the commodity flows among the areas in three prefectures were estimated by the gravity-RAS method for each sector. Finally, we compiled one MRIOT from each IOT and the commodity flow matrix of each sector.

Using the estimated MRIOT of the Tokai Region, we compared the output structures of each area by an RCA index. Nagoya City has the edge in tertiary industries as the core city of the region. Owari and Nishi-mikawa in Aichi Prefecture are well known for their machinery industries, especially motor vehicle and electric industries. Second, we investigated the characteristics of economic linkage among areas in terms of the Average Propagation Lengths index, to measure the regional linkage strength. A simple 
regression of the APL index on the geographical distance shows a good positive correlation. We found that relatively wide areas surrounding Nagoya City have some linkage to Nagoya City, though the Hida area in Gifu Prefecture has little connection to it. The APL index showed its usefulness to measure the degree of spatial linkage among areas.

We were able to show that subdividing the prefecture's IOT to those of several small areas and integrating them into a MRIOT yields an analytical tool to solve how the region may be identified in terms of economic activities is not necessarily the same as for an administrative region.

\section{Endnotes}

${ }^{1}$ Ministry of Land, Infrastructure, Transport and Tourism, Japan

${ }^{2}$ Ministry of Economy, Trade, and Industry, Japan

${ }^{3}$ Ministry of Internal Affairs and Communications, Japan

${ }^{4}$ There are several variations of the Location Quotient model for the estimation of the export and import of the region (see Miller and Blair (2009)).

${ }^{5}$ Japanese IOTs, national and regional, include "consumption expenditure outside households" as the exogenous sector, in both value-added parts and final demand parts. We estimate them in the value-added part assuming that the ratio to output for each sector is the same as those of the prefecture. We are able to acquire the total value in the final demand part by summing the sectoral values in the value-added part. Then each value of the item in the final demand part is estimated by multiplying the total value by the corresponding share value, assuming the share values are the same for all areas in the prefecture.

${ }^{6}$ Actually, there are not two areas for two prefectures but 14 areas for three prefectures in all.

${ }^{7}$ Here we adopted the adjusting rule that the larger sum is adjusted to the smaller sum by decreasing each item proportionally. As a result, either export shares or import shares are modified from the estimated values.

${ }^{8}$ There are some variations to show the distance between regions: geographical distance, time distance, and cost distance, and so on. Yamada and Owaki (2012) adopted the geographical distance. They measured the distance $L^{r s}$ between two points, each of which belongs to the different regions to be measured, by the root searching in the Google website. Then they calculated the average distance $\bar{L}^{R S}$ with the weight of the employment number as follows:

$$
\bar{L}^{R S}=\frac{\sum_{r \in R} \sum_{s \in S} L^{r s} E^{r} E^{s}}{\sum_{r \in R} \sum_{s \in S} E^{r} E^{s}}
$$

${ }^{9}$ The average distances were calculated from the distance between municipals that belonged to each area with employment weights.

\section{Additional files}

Additional file 1: Estimated transaction matrix.

Additional file 2: Estimated IOT for Tokai Region. 


\section{Additional file 3: Output structure of Aichi Prefecture. \\ Additional file 4: Output structure of Gifu Prefecture. \\ Additional file 5: Output structure of Mie Prefecture.}

\section{Competing interests}

The author declares that he has no competing interests.

\section{Acknowledgements}

The original version of this paper was presented at the 22nd International Input-Output Conference held in Lisbon Portugal, from 15th to 18th July 2014. The author appreciates the anonymous referees for their valuable comments and suggestions. This study was financially supported by the Chukyo University Research Fund (No. 1410813).

Received: 4 February 2015 Accepted: 20 July 2015

\section{Published online: 30 July 2015}

\section{References}

Asia Pacific Institute of Research (2012) Compilation of 2005 Kansai interregional input-output table and its application (in Japanese)

Chubu Regional Institute for Social and Economic Research (2011) 2005 Chubu Region interregional input-output table (in Japanese)

Dietzenbacher E, Romero I (2007) Production chains in an inerregional framework: identification by means of average propagation lengths. Int Reg Sci Rev 30(4):362-383

Dietzenbacher E, Remero Luna I, Bosma NS (2005) Using average propagation lengths to identify production chains in the Andalusian economy. Estud Economia Apl 23(2):405-422

Hagiwara T (2012) Compilation of 47-prefectures' interregional input-output table and its application. Kobe Univ Econ Rev 58:33-46 (in Japanese)

Hitomi K (2008) Development of multi-regional input output table for 47 prefectures in Japan. CRIEPI Res Rep. Y07035 (in Japanese)

Ishikawa Y (2004) A three-region interregional input-output model using non-survey technique. J Infrastructure Plann Manage 758(4-63):45-55 (in Japanese)

Ishikawa Y, Miyagi T (2003) Analysis of the input-output structure using multi-prefectural input-output table of Japan. Stud Reg Sci 34(1):139-152 (in Japanese)

Kansai Institute for Social and Economic Research (2008) Compilation of 2000 Kansai interregional input-output table (in Japanese)

Kronenberg T (2009) Construction of regional input-output tables using nonsurvey methods, The role of cross-hauling. Int Reg Sci Rev 32(1):40-64

Lahr ML (1993) A review of the literature supporting the hybrid approach to constructing regional input-output models. Econ Syst Res 5(3):277-293

Miller RE, Blair PD (2009) Input-output analysis: foundations and extensions. Cambridge University Press, New York

Nakano S, Nishimura K (2007) Estimation of multiregional transactions in partitioning regional input-output table. Sangyo Renkan (Input-Output Analysis) 15(3):44-53 (in Japanese)

Nakano S, Nishimura K (2013) A nonsurvey multiregional input-output estimation allowing cross-hauling: Partitioning two regions into three or more parts. Ann Reg Sci 50:935-951

Nomura J, Kinoshita M, Saito H, Asahi S (2011) Economic impacts of trans-regional tourists' expenditures utilizing multiregional I-O table of Yamaguchi Prefecture, Japan. Sangyo Renkan (Input-Output Analysis) 19(3):72-93 (in Japanese)

Sargento ALM, Ramos PN, Hewings GJD (2012) Inter-regional trade flow estimation through non-survey models: an empirical assessment. Econ Syst Res 24(2):173-193

Takahata Y (1992) Interregional I-O table of Hokkaido Prefecture. Sangyo Renkan (Input-Output Analysis) 3(3):24-29 (in Japanese)

Tohoku Region Advancement Center (2011) Report on the Tohoku multi-regional input-output table (in Japanese)

Tsubouchi T (1991) Interregional I-O table of Ehime Prefecture. Sangyo Renkan (Input-Output Analysis) 2(1):35-42 (in Japanese)

Yamada M (1996) An interregional input-output table of Mie Prefecture, Japan: estimation and applications. J Appl Input-Output Anal 5(4):52-67

Yamada M (2010) Compilation of 2000 inter-regional input-output table for Tokai Region. Chukyo Econ Rev Chukyo University 21:59-82 (in Japanese)

Yamada M (2013) Estimation of the interregional commodity flows by gravity-RAS method: A case of Aichi Prefecture, Japan. Chukyo University, Institute of Economics, Discussion paper 1301 (in Japanese)

Yamada M, Y Owaki (2012) Estimation of 2005 Aichi Prefecture's inter-regional input-output table. Chukyo University, Institute of Economics, Discussion paper 1205 (in Japanese) 